\title{
A crítica ao subjetivismo idealista em Marxismo e filosofia da linguagem
}

Cristiane Lenz ${ }^{1}$

\begin{abstract}
The work of Valentin Volochínov, Marxism and Philosophy of Language (2009), is fundamental for the studies of language in what concerns to the comprehension of language under a materialistic perspective, which takes into account its material and ideological nature. It is important to understand that the author starts from the critique on different theoretical tendencies to the development of their conception of language. Thus, he reflects on two main trends of the linguistic philosophical thought, which they designate as abstract objectivism and idealistic subjectivism. Reading the critique on these trends is fundamental to the comprehension of the development of their conception of language, in relation with ideology. We consider that, to make a deep reading, it is necessary to seek the sources on which this critique lies. Therefore, we propose the reading of a representative philosopher of idealistic subjectivism. It is Karl Vossler, in The spirit of language in civilization (1932). In this limit of space, we will stand only on the investigation of the work of this representative of one trend of the linguistic philosophical thought, the idealistic subjectivism, not disregarding the importance of a similar investigation into the abstract objectivism. Keywords:language; individualistic subjectivism; materialist perspective.
\end{abstract}

Resumo:A obra de Mikhail Bakhtin e Valentin Volochínov, Marxismo e Filosofia da Linguagem (2009), é fundamental para os estudos da linguagem no que tange à compreensão da língua sob uma perspectiva materialista, que leve em conta a sua natureza material e ideológica. É importante compreender que os autores partem da crítica sobre diferentes tendências teóricas para o desenvolvimento da sua concepção de língua. Assim, contemplam duas principais tendências do pensamento filosófico linguístico, as quais denominam objetivismo abstrato e subjetivismo idealista. Fazer a leitura da crítica a essas tendências é fundamental na compreensão da construção de sua concepção de língua, em relação com a ideologia. Consideramos que, para realizarmos uma leitura aprofundada, é necessário buscarmos as fontes sobre as quais essa crítica recai. Por conseguinte, propomos a leitura em torno de um dos representantes do subjetivismo idealista. Trata-se de Karl Vossler, citado por Bakhtin / Volochínov, com sua obra The spirit of language in civilization (1932). Neste limite de espaço, nos deteremos unicamente na investigação da obra desses representantes de uma tendência do pensamento filosófico linguístico, o subjetivismo idealista, não desconsiderando a importância de proceder à investigação semelhante em torno do objetivismo abstrato.

Palavras-chave:língua; subjetivismo idealista; perspectiva materialista.

1 Mestre em Estudos da Linguagem, Teorias do Texto e do Discurso, sob a supervisão da Profa. Ana Zandwais - Universidade Federal do Rio Grande do Sul.Membro do Grupo de Pesquisa 'História das Ideias: diálogos entre linguagem, cultura e sociedade.' 
Introdução

A obra Marxismo e Filosofia da Linguagem (2009), de M. Bakhtin e V. Volochínov, constitui um estudo basilar para a Filosofia da Linguagem, na medida em que levanta questionamentos sobre alguns dos problemas mais importantes na história dos estudos linguísticos. Alguns desses questionamentos e Teses propostos pelos autores estão hoje presentes nas principais pesquisas no interior das ciências da linguagem e repercutem também interdisciplinarmente. Nesse ínterim, a concepção material de língua, elaborada a partir de uma perspectiva marxista da linguagem e da tomada do signo por seu valor ideológico, é, talvez, o maior legado que esses autores tenham nos deixado, pois essa concepção é fundante de novas teorias acerca do sentido e da subjetividade, além do fato de que a língua tomada sob a ótica do seu funcionamento ideológico reconfigura o próprio ensino de língua materna e a torna um objeto de reconhecimento da história.

Ao passo que Marxismo e Filosofia da Linguagem é uma obra pioneira no tratamento de algumas das mais importantes questões dos estudos da linguagem e redimensiona a língua como objeto de estudo, ela também está vinculada ao pensamento filosófico-linguístico que vigorava na época de sua publicação. Mas não de forma a se apoiar em bases já existentes, e sim no sentido de criticar determinadas posições teóricas e, sobre essa crítica, construir suas teses.

Objetivamos, no presente artigo, aprofundar nossa reflexão sobre a crítica de Bakhtin / Volochínov (2009) em torno de uma corrente do pensamento filosófico-linguístico, o subjetivismo idealista.

Para compreender como essa crítica se desenvolve, procederemos à leitura de um de seus principais representantes, Karl Vossler, em sua obra SpiritofLanguage in Civilization(1932). É importante compreender que os autores fazem essa crítica a partir do que consideram ser os principais problemas que os estudos da linguagem não haviam sido capazes de resolver, ou seja, suas críticas fundamentam-se na necessidade de uma teoria que dê conta de considerar a língua como um objeto de estudo que leve em consideração sua natureza simbólica e ideológica. É partir dessa reflexão que damos continuidade ao nosso texto.

\section{Uma crítica a uma tendência do pensamento filosófico-linguístico}

O capítulo 4 de Marxismo e Filosofia da Linguagem (2009) questiona sobre o objeto de estudo da Filosofia da Linguagem. Os autores se perguntam: "No que consiste o objeto da Filosofia da Linguagem? Onde podemos encontrar tal objeto? Qual é a sua natureza concreta? Que metodologia adotar para estudá-lo? (...) Mas o que é a linguagem? O que é a palavra?" (p. 71) A partir desses questionamentos, os autores levantam hipóteses sobre como lidar com essas questões.

Estas hipóteses apontam para as dificuldades em dividir a língua como objeto de estudo em partes isoladamente observáveis. Nem o estudo do processo fisiológico de produção do som, nem da percepção sonora é capaz de resguardar o estatuto simbólico e ideológico da língua. Tampouco a atividade mental do locutor e do ouvinte caracteriza um processo em que seja possível encontrar a linguagem como "objeto específico" (op. Cit., p. 72). Assim, compreendemos que nem o aspecto físico, fisiológico ou psicológico da linguagem é suficiente para caracterizar a língua como um objeto específico de estudo. 
A partir disto, os autores questionam a forma de condução destes problemas por parte da Filosofia da Linguagem desenvolvida até então. Na seguinte passagem, encontramos a introdução à crítica feita às duas correntes do pensamento filosófico-linguístico:

[...] encontramo-nos em presença de duas orientações principais no que concerne à resolução de nosso problema, que consiste em isolar e delimitar a linguagem como objeto de estudo específico. Isto acarreta, por suposto, uma distinção radical entre estas duas orientações para todas as demais questões que se colocam em linguística. Chamaremos a primeira orientação de "subjetivismo idealista" e a segunda "objetivismo abstrato". (op. cit., p. 74)

A afirmação em itálico, grifos dos autores, explicita qual o problema principal posto em questão, que é o de delimitar de que forma a língua pode ser tomada como um objeto de estudo. Para tal reflexão, propõem-se a investigar duas orientações teóricas denominadas subjetivismo idealista e objetivismo abstrato ${ }^{2}$.

No presente artigo, propomos a leitura da crítica ao subjetivismo idealista, que tem entre os seus principais representantes Karl Vossler ${ }^{3}$. Sua obra Spirit of Language in Civilization ${ }^{4}$ nos permite identificar as características exploradas por Bakhtin / Volochínov (2009) e refletir sobre a forma de condução de alguns problemas dos estudos da linguagem no interior da corrente denominada subjetivismo idealista.

Vejamos como os autores caracterizam, fundamentalmente, essa orientação:

A primeira tendência [o subjetivismo idealista] interessa-se pelo ato de fala, de criação individual, como fundamento da língua (no sentido de toda atividade de linguagem sem exceção). O psiquismo individual constitui a fonte da língua. As leis da criação linguística - sendo a língua uma atividade ininterrupta, uma criação contínua - são as leis da psicologia individual, e são elas que devem ser estudadas pelo linguista e pelo filósofo da linguagem. (2009, p. 74)

Compreendemos que a noção de língua do subjetivismo idealista se constrói sobre a sua concepção de subjetividade. A primeira observação que podemos fazer é que o ato de fala encontra-se como o principal ponto de interesse de seus estudos, ou seja, a investigação do ato de fala está no cerne da compreensão da natureza da língua. Esse fato se relaciona com a forma com que essa orientação entende a concepção de sujeito. Para o subjetivismo idealista, a língua é uma criação individual, e se origina no interior do indivíduo. Aqui, o sujeito ocupa um lugar soberano que controla a expressão. O próprio termo criação linguística remete a algo que é criado em cada ato de enunciação. Bakhtin / Volochínov (2009) elaboram proposições que sintetizam as posições fundamentais dessa orientação. Trazemos a primeira e a segunda proposição, que parecem abrir caminho para pensar as concepções de língua e sujeito para o subjetivismo idealista:

2 Em nota, os autores destacam a dificuldade de uma nomenclatura adequada, visto que essa denominação não recobre todo o conteúdo e a complexidade das duas orientações. (Bakhtin / Volochínov, 2009, p. 74)

3 Karl Vossler foi um linguista alemão, seguidor das ideias de Benedetto Croce, e viveu entre o final do século XIX e primeira metade do século XX.

4 Utilizamos a edição em inglês de 1932. Sabemos que essa obra foi publicada no início do século XX, sob a influência do pensamento de Wilhelm Von Humboldt e Benedetto Croce. Em meio à chegada dos estudos linguísticos saussurianos, a obra de Vossler não convergiu para as abordagens positivistas da linguagem. Bakhtin / Volochínov (2009, p. 77), chamam a atenção para este fato: "Atualmente, a primeira tendência da filosofia da linguagem, tendo rejeitado as vias do positivismo, está a caminho de desabrochar novamente e de alargar a visão destes problemas na escola de Vossler." 


\section{Conexão Letras}

1. A língua é uma atividade, um processo criativo ininterrupto de construção ("energia") materializa sob a forma de atos individuais de fala.

2. As leis da criação linguística são essencialmente as leis da psicologia individual. (op. cit., p. 74)

Com base na proposição acima compreende-se a língua como um processo de criação individual, que se dá no ato de fala. Nesse momento, recorremos a um dos representantes do subjetivismo idealista para compreendermos de que forma essa concepção se constrói. Bakhtin / Volochínov trazem a escola de $\operatorname{Vossler}^{6}$ como uma das representações que lhes era contemporânea. Atentemos para as seguintes afirmações:

Atualmente, a primeira tendência da filosofia da linguagem, tendo rejeitado as vias do positivismo, está a caminho de desabrochar novamente e de alargar a visão destes problemas na escola de Vossler. [...] O que caracteriza primordialmente a escola de Vossler, é a negação categórica e de princípio do positivismo linguístico, que não consegue ver mais além das formas linguísticas (em particular as fonéticas, as que são positivas) e do ato psicofisiológico que as engendra. $(2009$, p. 77$)$

A partir desse excerto, o primeiro aspecto que nos chama a atenção é o fato de que os princípios da escola de Vossler se opõem a uma concepção positivista de língua, o que Bakhtin / Volochínov postulam como a característica fundamental do objetivismo abstrato (2009).

Na leitura de SpiritofLanguage in Civilizaton $^{7}$, o próprio uso do termo espírito ${ }^{8}$ se afasta do positivismo, ao manter suas investigações em uma linha metafísica e conceder às questões linguísticas um caráter subjetivista e idealista. Para Vossler, uma comunidade linguística se constrói sobre uma série de elementos que a caracterizam como uma língua nacional, o que constitui o espírito nacional. Bakhtin/ Volochínov (2009) criticam o uso do termo 'espírito nacional' principalmente ao longo de sua obra, afirmando que é uma tendência comum dos idealistas buscarem apoio na ideia de espírito para explicar questões de estilo e significação na língua.

Para Bakhtin / Volochínov, ao contrário, a língua deve ser considerada sob uma perspectiva histórica e investigada como um objeto material, o que significa tomar as suas relações com o que é de ordem social e histórica.

Vossler (1932) reflete sobre o que garante às línguas as suas especificidades, já que, desde que todos os indivíduos possuem o mesmo órgão fonador, essa explicação não pode ser de ordem fisiológica, conforme a seguinte afirmação:

5 Segundo nosso entendimento, isto se refere ao conceito aristotélico energeia, visto que, segundo esse conceito, a energia é a atividade, é o que possibilita a práxis. Isso tem a ver com a atividade individual de criação linguística, proposta pelo subjetivismo idealista, de acordo com a crítica de Bakhtin / Volochínov.

6 Karl Vossler foi um linguista alemão, seguidor das ideias de Benedetto Croce, e viveu entre o final do século XIX e primeira metade do século XX.

7 Utilizamos a edição em inglês de 1932. Sabemos que essa obra foi publicada no início do século XX, sob a influência do pensamento de Wilhelm Von Humboldt e Benedetto Croce. Em meio à chegada dos estudos linguísticos saussurianos, a obra de Vossler não convergiu para as abordagens positivistas da linguagem.

8 Bakhtin / Volochínov(2009) mencionam o pensamento de Wilhelm Dilthey, que se formou sobre um terreno idealista, e se preocupou com as ciências do espírito. Ao longo dos capítulos 3, 4 e 5 de Marxismo e Filosofia da Linguagem, há menções ao trabalho de Dilthey que encaminham a crítica à ideia de espírito, pois essa noção se afasta de uma concepção materialista da linguagem e está no cerne dos estudos idealistas, por conferir à personalidade individual a responsabilidade pela expressão. 
Since all men possess in their ear and tongue the natural organs of speech, the particular linguistic equipment that distinguishes these peoples from one another has to be sought elsewhere than in the human senses. It is to be found in the Latin, Greek, French, German tongue, not in the tongue as such $[\ldots]^{9}($ p. 115)

Essa passagem nos chama a atenção também por estar na direção contrária aos estudos saussurianos, cujo objetivo era fundar uma linguística geral. Compreendemos que Vossler (op. cit.), ao falar na especificidade de cada língua, o latim, o francês, o alemão, etc., considera a necessidade da investigação sob a perspectiva de cada língua, para buscar as características próprias a cada uma delas, e não na língua em si, conforme afirma. Mas onde reside esse caráter da língua nacional? Vossler explica da seguinte forma:

Human language is instrumentated differently by the Frenchman and the German. For instance, the former will emphasize something syntactically, where the latter uses a gesture or an intonation; where the one uses the future, the other uses the present; where one needs the subjunctive or a partitive article, the other is content with the indicative, or will dispense with an article. ${ }^{10}(1932$, p. 115)

Nesse sentido, não haveria a investigação da língua em geral, mas sim das especificidades das línguas de cada nação. Na busca pela explicação dessas diferenças, o autor conclui que elas são historicamente condicionadas. No entanto, postula que não é uma relação causal entre as línguas e a história, e acaba por conferir às especificidades das línguas uma explicação que se vincula ao "caráter nacional", conforme observamos na seguinte passagem: "All these differences are historically conditioned; but in the final instance they are connected with the type of mind predominating in that particular language community, that is, with the 'national character'."'I1 (op. cit., p. 115)

Por fim, o autor acaba por observar que o caráter nacional não é o que faz com que uma língua se caracterize de uma forma e não de outra, mas sim a língua em si constrói esse caráter. Então, parece-nos que Vossler nos instrui acerca do caráter nacional, para depois explicar que não é esse caráter o responsável por fazer de uma língua o que ela é, mas sim, a língua constrói esse caráter no seu próprio uso pelos sujeitos. Compreendemos isso a partir do seguinte:

The French do not speak French because they have a French attitude, type of mind, or character, but simply because they speak. Their language becomes French, not because some outside influence, but because of themselves; and through their speech, whatever and however it be, their national character is embodied and realized in what we call the French language $^{12}$. (op. cit., p. 116)

9 Tradução de responsabilidade da autora: "Na medida em que todos os homens possuem em seu ouvido e em sua língua os órgãos naturais da fala, o equipamento linguístico particular que distingue essas pessoas umas das outras devem ser buscadas em outro lugar que não nos sentidos [fisiológicos] humanos. Deve ser encontrado na língua latina, grega, francesa ou alemã, não na língua em si [...]”."

10 Tradução de responsabilidade da autora: "A língua humana é instrumentada diferentemente pelo indivíduo francês ou pelo alemão. Por exemplo, o primeiro irá enfatizar algo sintaticamente, enquanto o segundo usa um gesto ou uma entonação; enquanto um usa o futuro, ou outro usa o presente; enquanto um precisa do subjuntivo ou de um artigo partitivo, o outro se contenta com o indicativo ou dispensa o artigo."

11 Tradução de responsabilidade da autora: "Todas estas diferenças são historicamente condicionadas; mas em última instância elas são conectadas com o tipo de mente predominante naquela comunidade linguística particular, ou seja, com o caráter nacional."

12 Tradução de responsabilidade da autora: "Os franceses não falam francês porque eles têm uma atitude, um 
No mínimo duas questões nos chamam a atenção sobre essa passagem. A razão pela qual uma língua existe como tal pode ser explicada pelo uso de seus falantes, o que reconhecemos na afirmação de que "Their language becomes French [...] because of themselves." (op. cit., p. 116) A partir disso, o caráter nacional - desses falantes - se realiza através da língua. Mas novamente nossa pergunta acerca da natureza desse caráter nacional não foi totalmente respondida. Um dos motivos dessa dificuldade reside justamente no fato desse caráter não ser de ordem material, ou, pelo menos, não se apresentar a nós de uma forma que possa ser compreendido sem estar atrelado ao conceito de "espírito".

Então, nos encaminhamos para a compreensão de que Vossler coloca o falante no cerne dos seus estudos linguísticos, já que reconhece que são estes os responsáveis por constituir a língua, a partir da forma como a utilizam. Assim, também vamos compreendendo de que forma esse falante se caracteriza no pensamento desse autor.

Até agora, encontramos a primazia da relação entre língua e interioridade do sujeito, em detrimento de uma relação que aproxime língua e exterioridade. Parece que para Vossler, a própria nação poderia ser entendida como um sujeito (1932). E esse sujeito também se situa nos limites do seu "interior", ou seja, a língua nacional é concebida de acordo com o espírito nacional inculcado nesse sujeito. Essa concepção traz importantes considerações. Trazemos, neste espaço, uma série de considerações levantadas por Vossler, que são de suma importância para os estudos da linguagem.

Primeiramente, o autor reflete sobre a predominância de uma língua sobre outra. Segundo ele, desde a Grécia antiga ou a Idade Média, as guerras não objetivavam apenas poder e riqueza, mas também decidiam a cultura que iria predominar, e, com isso, a língua. No entanto, na década de 1930, período da primeira edição desta obra, o autor acredita que os povos não deixariam sua língua ser extinta facilmente, pois é possível observar que há países lutando pela preservação de sua língua de origem.

Esse sentimento de preservação teria a ver com questões de consciência acerca das questões identitárias de um povo, como observamos em: "A language is defended more obstinately the more alive the feeling and theclearer the counsciousness that it is a matter of preserving one'sown tribal, racial and national characteristics."13 (1932, p. 119)

Além disso, Vossler faz considerações sobre o fato de que a língua é capaz de unir os homens (p. 120) e reflete de uma forma muito interessante sobre as situações ao longo da história em que uma língua foi proibida a um povo.

Segundo ele, essas proibições unem de tal forma os homens que pertencem a essa ou aquela comunidade linguística que essas comunidades tornam-se cada vez mais poderosas em seu orgulho. Além disso, qualquer palavra pronunciada na língua proibida torna-se um gesto de guerra contra o inimigo.

Outra questão levantada por Vossler (op. cit., p. 17) é sobre a relação que os falantes mantêm com a sua primeira língua. Ele chama a atenção para o fato de que chamamos "mother tongue" - língua mãe - a língua que aprendemos com a figura materna, no seio da família. Esta língua seria aquela com a qual tivemos nossa identificação desde a infância. A partir disso, o autor reflete sobre a relação desta com a aquisição da segunda língua. Atentemos para o seguinte excerto:

tipo de mente ou um caráter francês, mas simplesmente porque eles falam. A sua língua se torna francês, não por cause de uma influência externa, mas por causa deles mesmos; e através do seu discurso, o que for e da forma que for, o seu caráter nacional será incorporado e percebido no que nós chamamos língua francesa."

13 Tradução de responsabilidade da autora: "Uma língua é defendida mais obstinadamente quanto mais vivo estiver o sentimento e mais clara estiver a consciência de que é uma questão de preservação da tribo, da raça de características nacionais." 
"Even when he [the Frenchman] incorporates foreign words they become French to him; and when he learns English or Chinese, he does it on a French basis. Through practice and habituation he may achieve citizenship in any number of languages; but his spiritual home remains French, which he may deny or forget, but which he can no more lose than he can lose the experiences of his childhood". ${ }^{14}$ (op. cit., p. 116)

Nessa reflexão, a primeira língua aparece em uma posição inabalável no espírito dos falantes. É dessa forma que ela se apresenta como a língua nacional que carrega o caráter nacional sobre o qual falamos anteriormente. $\mathrm{O}$ autor observa também que a segunda língua é uma língua técnica, aprendida, enquanto que a primeira língua é experimenta$d a$ - "experienced language" (op. cit., p. 115). Entendemos experimentada como vivida, apreendida através da experiência. Segundo Vossler, esse processo de língua experimentada só acontece uma vez na vida, ou seja, após este processo, só há a aquisição da língua técnica, que seria a segunda língua.

É interessante compreender de que forma o autor caracteriza a primeira língua:

Experienced language, therefore, on the one hand has the subjective, limited, and natural affective value of childhood: on the other, a value of achievement, which is objective, spiritual, and has a general human significance. ${ }^{15}$ (op. cit.,p. 117)

Com isso, compreendemos a forma idealista com que esse pensamento caracteriza a língua nacional. Parece-nos que o raciocínio é o de que, desde que essa língua é experimentada, e assim apreendida, na infância, ela ocupa um lugar no interior espiritual de seus falantes, e mantém com eles uma relação mediatizada pelo interior. Nesse sentido, a língua materna ocupa um lugar hegemônico, como se fosse uma língua única, e esse entendimento parece consistir em uma visão idealista.

Nesse momento, compreendemos que há uma caracterização sobre o que constitui o sentimento nacional em relação a essa primeira língua, que seria a língua nacional. O sentimento do falante por essa língua se apoia em uma relação com sua infância, em que a língua seria um dom herdado dos pais, e também seria um patrimônio cultural, visualizado por cada um como a realização do espírito nacional. (op. cit.). A partir dessa reflexão, o autor compreende que: "National feeling, then, is dependent on national language, and oscillates between love and pride. The value we attach to our national language is our national pride." ${ }^{\prime 6}$ (op. cit., p. 117, 118) Com estas reflexões, Vossler (op. cit.) se encaminha para o tratamento das questões de ordem estilística.

Segundo Bakhtin / Volochínov (2009), esta preocupação é a mais latente no pensamento de Vossler. Os autores chamam a atenção para o fato de que, ao considerar o ato individual de fala como o objeto de estudo do linguista, Vossler prima pelo caráter artístico e estético dessa criação linguística. Eles afirmam que, para o autor alemão:

14 Tradução de responsabilidade da autora: "Até mesmo quando ele [o homem francês] incorpora palavras estrangeiras elas se tornam francesas para ele; e quando ele aprende inglês ou chinês, ele o faz em uma base francesa. Através da prática e do hábito ele poderá atingir a cidadania em um certo número de línguas; mas seu espirito permanece francês, o que ele poderá negar ou esquecer, mas nunca poderá perder, assim como não perde as experiências de sua infância."

15 Tradução de responsabilidade da autora: "A língua experimentada, portanto, de um lado tem o valor subjetivo, limitado e natural da infância: por outro lado, um valor de conquista, que é objetivo, espiritual, e tem um significado humano geral."

16 Tradução de responsabilidade da autora: "o sentimento nacional, então, é dependente da língua nacional, e oscila entre amor e orgulho. O valor que nós conferimos a nossa língua nacional é o nosso orgulho nacional." 
O motor principal da criação é o "gosto linguístico", variedade particular do gosto artístico. O gosto linguístico é justamente esta verdade linguística absoluta que dá ida à língua e que o linguista se esforça por descobrir em cada fato de língua, a fim de dar-lhe uma explicação adequada. (Bakhtin / Volochínov, 2009, p. 77)

O estilo, para Vossler, recai nas questões da língua nacional na medida em que uma segunda língua não tem, em primeira instância, o poder de refletir os sentimentos e o orgulho nacional. Segundo ele, tudo o que soa bonito, feio ou estranho nos sons da língua estrangeira, seria a ornamentação dessa língua. (1932) Essa ornamentação aparece descrita da seguinte forma:

It is the particular aspect of a language in general, its characteristic, individual, national, provincial, idiomatic nature, as opposed to its universal and personal nature. In its striving for unity and objectivity language is universal and personal, in its urge towards multiplicity and ornamentation it is individual ${ }^{17}$. (grifos nossos) (op. cit., p. 135)

Nessa reflexão, a ornamentação seria o aspecto individual, as características nacionais e sua natureza idiomática, em oposição ao aspecto universal da língua. No entanto, compreendemos que individual não se opõe à nacional, pois, segundo o pensamento de Vossler, a língua nacional está incrustada no sentimento e orgulho nacional de cada um, e essa é uma característica que deriva de um imaginário, pois é a relação de cada falante com seu sentimento nacional. Desse modo, a língua seria universal na busca pela unidade, mas seria individual na sua 'ornamentação'.

Nesse sentido, a língua é tratada de forma universalizada e homogênea, e o estilo é pensado dominantemente em termos de padrão estético, de tal forma que as questões que remetem à natureza heterogênea da língua e a sua não unidade são esquecidas. Isso configura uma visão idealista, e, portanto, irreal da língua.

O caráter pessoal da língua se refere ao falante que utiliza todos os seus sentidos para pensar, falar, ouvir, entender e responder, e que se situa em uma comunidade linguística. Ou seja, ao situar-se em uma comunidade, há a busca pela unidade da qual o autor nos fala, a busca pela troca linguística através daquilo que é comum. O que é da ordem do pessoal está ligado ao estilo. A busca pela unidade está associada ao que é da ordem do universal.

A partir disso, chegamos a um raciocínio sobre o pensamento de Vossler que nos encaminha para a compreensão acerca dos conceitos de língua e subjetividade no subjetivismo idealista. Atentemos para a seguinte passagem:

[...] if we wish to do justice to the special character of national languages, they have to be judged rather as styles than as languages. Nations are individuals, and as such they can express themselves through language and style, though they cannot speak. It is an illusion to think that the language of some particular nation can be spoken by the nation as such. The speakers are the many persons that constitute it. ${ }^{18}(1932$, p. 137)

17 Tradução de responsabilidade da autora: "É o aspecto particular de uma língua em geral, sua característica, sua natureza individual, nacional, provincial e idiomática, em contraste com a sua natureza individual e pessoal. Na sua luta por unidade e objetividade a língua é universal e pessoal, na sua urgência por multiplicidade e ornamentação ela é individual."

18 Tradução de responsabilidade da autora: “[...] se nós desejamos fazer justiça ao caráter especial das línguas nacionais, elas têm de ser julgadas muito mais enquanto estilos do que enquanto línguas. Nações são indivíduos, e como tais elas podem se expressar pela língua e estilo, apesar de não poderem falar. É uma ilusão 
Essa reflexão é essencial para nossa compreensão, pois traz dois pontos importantes. Primeiro, é possível visualizar o que nos ensinam Bakhtin / Volochínov acerca da preocupação de Vossler acerca das questões estilísticas e artísticas, conforme citamos anteriormente. Para este autor, as características de estilo devem conduzir os estudos linguísticos, considerando as relações entre língua nacional e estilo.

Sobre essa relação, ele explica que o que deve ser questionado não é o que é permitido e o que é proibido na língua, como o fazem os gramáticos. Mas deve-se questionar o que se objetiva e quais são suas possibilidades. (op. cit.) Assim, esses aspectos constituem uma relação de forças na constituição do caráter estético da língua. A partir disso, o autor afirma: "In every national language there is an aesthetic will [...]"19(op. cit., p. 137)

Essa força é atribuída ao gênio da língua ou espírito ${ }^{20}$. Esse gênio ou espírito da língua diz respeito a um estilo nacional, a um estilo de época, que existe para cada indivíduo como o seu estilo próprio. Nesse sentido, a força da língua reside na sua estética. Essa estética estaria, segundo esse pensamento, vinculada a um imaginário de identidade nacional. É nessa concepção que se perde a natureza social e histórica da língua.

O segundo ponto se refere ao fato de que o autor considera, no nosso entendimento, uma nação como um indivíduo, pois ela só fala através de seus falantes. Nesse sentido, a ideia de nação se personifica nas pessoas que a constituem, pois a língua nacional não pode ser falada senão por elas. Essa reflexão encontra o raciocínio de que a língua está em poder dos falantes, em poder de todos e de cada um, ou seja, conforme refletimos mais acima, está em poder de todos no sentido de buscar uma unidade, mas em poder de cada um por conta de suas formas estilísticas.

Então, nessa concepção, aos falantes é concedido o papel de maior importância na construção da língua nacional. No entanto, o problema, desde esta ótica, recai em considerar esse falante como detentor da língua, como senhor do seu pensamento e do seu dizer. Nesse sentido, a língua se engendra no seu interior, que é o lugar onde estão guardadas as disposições de um espírito nacional.

É nesta reflexão que reside, principalmente, o caráter idealista do pensamento de Vossler, segundo a crítica de Bakhtin / Volochínov (2009), que descrevem o primeiro equívoco do subjetivismo idealista:

O subjetivismo idealista [...] só leva em consideração a fala. Mas ele também considera o ato de fala como individual e é por isso que tenta explicá-lo a partir das condições da vida psíquica individual do sujeito falante. E esse é o seu próton pseudos. (op. cit., p. 113)

Essa perspectiva da fala como uma enunciação de ordem particular, individual no sentido de que se constitui como um estilo que é pessoal e que existe no interior dos indivíduos, é criticada por Bakhtin / Volochínov (op. cit.) no sentido de que em uma leitura materialista a língua não pode ser concebida fora do âmbito do que é de ordem histórica

pensar que a língua de uma nação em particular é falada pela nação como tal. Os falantes são as pessoas que a constituem."

19 Tradução de responsabilidade da autora: "Em toda língua nacional há uma força estética [...]".

20 Segundo Vossler (1932), esses termos foram usados pelos românticos. Já os positivistas refutaram essas expressões porque elas não seriam próprias de uma ciência. $\mathrm{O}$ autor, por sua vez, utiliza-os não como uma referência a um ser mitológico, mas sim como uma força. Bakhtin / Volochínov (2009) postulam que a orientação do subjetivismo idealista está ligada ao romantismo, que formou os primeiros filólogos, "os primeiros a tentar reorganizar a reflexão linguística sobre a base da atividade mental em língua materna [...]” (p. 114) No entanto, segundo os autores, estava além de suas forças reestruturar uma forma de pensar sobre a língua que já se mantinha há séculos. 
e ideológica. Além disso, para esses autores, a estética da língua não é uma questão de escolha individual, mas sim se constrói ao longo de sua história.

Para além da questão individual, outro problema na concepção do subjetivismo idealista é o fato de que há uma homogeneização da língua. A consideração de uma língua nacional e de um caráter nacional apaga o fato de que uma comunidade nacional se constrói de forma heterogênea, e os indivíduos fazem uso da língua de formas diferentes.

Um mesmo país, com o mesmo sistema econômico e a mesma organização sociopolítica oferece condições de existência diversas para diferentes indivíduos. Isso porque um sistema como o capitalismo se caracteriza por suas contradições. Na medida em que os valores e as necessidades variam no interior de uma mesma sociedade, conforme os interesses de classe variam, os indivíduos fazem uso da mesma língua, mas de modos divergentes. Dessa forma, não haveria como afirmar um estilo nacional em uma nação heterogeneamente constituída.

Bakhtin / Volochínov assim descrevem os princípios do pensamento de Vossler, como representante do subjetivismo idealista:

Compreende-se que não é um sistema linguístico acabado, no sentido da totalidade dos traços fônicos, gramaticais e outros, mas sim o ato de criação individual da fala (Spracheals Rede) que será para Vossler o fenômeno essencial, a realidade essencial da língua. (2009, p. 78)

Dessa forma, para Vossler, segundo os autores nos explicam, o que importa, do ponto de vista da evolução da língua, é a realização estilística e as formas de caráter individual que dizem respeito ao ato de fala. "Todo fato gramatical foi, a princípio, estilístico. É a isto que se liga a ideia vossleriana da primazia do estilístico sobre o gramatical." (op. cit., p. 78)

Em nossa compreensão, tal concepção da língua é notável para os estudos da linguagem. se por um lado o pensamento de Vossler refere-se a uma criação linguística como um ato que tem seu ponto de origem no interior do falante, e isso configura uma concepção idealista se nós entendermos a língua sob uma perspectiva materialista. Por outro lado, reconhecer um estilo particular que é construído de acordo com um sentimento nacional, por mais que o termo sentimento não se refira a uma abordagem materialista, e considerar este estilo em detrimento da gramática, constitui uma reflexão altamente importante. Tal reflexão abre caminho para pensar uma variedade de questões, tais como: as relações entre língua e subjetividade; uma concepção de subjetividade relacionada com aspectos nacionais, e, portanto, materiais; o papel dos indivíduos inseridos em condições sociais e histórias nos processos de enunciação.

\section{Considerações finais}

Consideramos que as reflexões em torno da crítica de Bakhtin / Volochínov (2009) ao subjetivismo idealista e a leitura de um de seus principais representantes, Karl Vossler, pode nos levar a uma melhor compreensão sobre os desafios dos estudos da linguagens. Além disso, as considerações dos autores reafirmam a necessidade de um trabalho sob uma perspectiva materialista da língua.

Para o subjetivismo idealista, o foco nos estudos da linguagem recai na fala com um ato individual de enunciação, assim como na unidade da língua nacional e no estilo como valor estético. 
Segundo Bakhtin / Volochínov, (2009, p. 113), ao considerar o ato de fala um ato individual de enunciação, esta tendência “(...) tenta explicá-lo a partir das condições da vida psíquica individual do sujeito falante." Reconhecemos aqui a crítica principal de Bakhtin / Volochínov sobre esta tendência do pensamento filosófico-linguístico. Os autores concluem:

Na realidade, o ato de fala, ou, mais exatamente, seu produto, a enunciação, não pode de forma alguma ser considerado como individual no sentido estrito do termo; não pode ser explicado a partir das condições psicofisiológicas do sujeito falante. A enunciação é de natureza social. (op. cit., p. 113)

Como podemos compreender, Bakhtin / Volochínov (op. cit.) constroem sua tese partindo da observação de tendências do pensamento no interior da Filosofia da Linguagem. Portanto, é essencial que qualquer trabalho em torno de sua obra leve em consideração tais relações.

Em relação ao trabalho de Vossler, a partir da presente investigação em torno de Spirit of Language in Civilization(1932), podemos afirmar a sua importância para os estudos da linguagem, na medida em que levanta questões e debates a partir de uma perspectiva única. Embora uma abordagem individualista do conceito de subjetividade possa ser considerada idealista, compreendemos que em muitos aspectos esse autor é pioneiro e original no seu pensamento.

Em uma época em que os estudos linguísticos tinham grandes preocupações de ordem formal, e o Curso de Linguística Geral havia sido publicado pela primeira vez quinze anos antes, Vossler levantou questões sobre a fala em detrimento de uma abordagem sobre a língua desde uma ótica universalistal e, mais do que isso, sobre o discurso de cada um, destacando a importância de investigar as relações entre língua e subjetividade. Este pensamento fica claro quando o autor, no início do capítulo II de Spiri tof Language in Civilization(1932, p. 7), afirma que:

To begin with, there is actually no language, but only speech: my speech, your speech, our speech now and here, to-day and yesterday. But our speech is not yet a language, it is at most conversation. And even this would have to be doubted if my speech were not heard and understood and answered in some way by someone else. If I were the only one in the whole world who spoke, there would not only be no language, there would not even be speech, not even my speech. How can I be sure, how can I know that I am speaking when no one hears me, no one understands, no one answers - no one; therefore not even myself??

Com estas palavras, finalizamos a presente reflexão, conscientes de que este é somente um excerto do que deve ser uma ampla investigação.

21 Tradução de responsabilidade da autora:"Para começar, não há realmente uma língua, somente um discurso: meu discurso, seu discurso, nosso discurso agora e aqui, hoje e ontem. Mas nosso discurso não é ainda uma língua, é em sua maior parte conversação.E até mesmo isto teria que ser duvidado; se meu discurso não foi ouvido e entendido e respondido de alguma forma por alguém. Se eu fosse o único no mundo inteiro que falasse, não só não haveria língua, como não haveria discurso, nem mesmo meu discurso. Como eu posso ter certeza, como eu posso saber que eu estou falando quando ninguém me ouve, ninguém entende, ninguém responde - ninguém; portanto, nem mesmo eu?" 


\section{Referências}

BAKHTIN, Mikhail (VOLOCHINOV, V.) Marxismo e filosofia da linguagem. Problemas fundamentais do método sociológico na Ciência da linguagem. São Paulo: Ed. Hucitec, 2009.Trad.LAHUD, Michel, FRATESCHI, Yara et al.

BESNIER, Bernard. A distinção entre praxis e poiêsis em Aristóteles. Analytica. v. 1, n. 3, 1996. Disponível em: https://revistas.ufrj.br/index.php/analytica/article/ download/394/351. Acesso em: 13 setembro 2016.

CROCE, Benedetto. Breviário de estética. São Paulo: Atena, [19--].

SAUSSURE, Ferdinand de. Curso de Linguística Geral. São Paulo: Cultrix, 1995.

VOLOCHÍNOV, V. N. Marxism and philosophy of language. New York: Seminar Press, 1973. Translated by Ladislav Matejka and R. Titunic.

VOSSLER, Karl. The spirit of language in civilization. London: Kegan Paul, 1932. 